\title{
Research on Ground Liquefaction and Structural Force Characteristics of Underground Utility Tunnels Under CLC Stratigraphic Model
}

Tian Tian ( $\sim$ bgdtt@emails.bjut.edu.cn )

Beijing University of Technology

aijun Yao

Beijing University of Technology

Yifei Gong

Beijing University of Technology

Yaozhen Guo

Metallurgical Corporation of China (China)

\section{Research Article}

Keywords: Utility tunnel, Finite-difference, Layered liquefiable soils, Burial depth, Soil liquefaction

Posted Date: September 15th, 2021

DOl: https://doi.org/10.21203/rs.3.rs-889520/v1

License: (c) (i) This work is licensed under a Creative Commons Attribution 4.0 International License.

Read Full License 


\title{
Research on Ground Liquefaction and Structural Force Characteristics of
}

\section{Underground Utility Tunnels Under CLC Stratigraphic Model}

Tian Tian ${ }^{\mathrm{a}, *}$, Aijun $\mathrm{Yao}^{\mathrm{b}}$, Yifei Gong ${ }^{\mathrm{c}}$, Yaozhen Guo ${ }^{\mathrm{d}}$

${ }^{a}$ Ph.D. Student, Beijing University of Technology, Beijing 100124, China (E-mail:

\section{bgdtt@emails.bjut.edu.cn)}

${ }^{\mathrm{b}}$ Professor, Beijing University of Technology, Beijing 100124, China (E-mail:

yaj@bjut.edu.cn)

${ }^{c}$ Ph.D. Student, Beijing University of Technology, Beijing 100124, China (E-mail:

\section{gongyifei@emails.bjut.edu.cn)}

${ }^{\mathrm{d}}$ Master, China Metallurgical Construction Research Institute Co., Ltd., Beijing 100124, China (E-mail:

gyzgyz131@163.com)

\begin{abstract}
:
Damages to underground structures due to liquefaction of the soils caused by cyclic loads such as earthquakes have always been an important issue in geotechnical underground engineering practices. This paper presents a numerical study of the utility tunnels at different burial depths in "Coh-Liq-Coh" horizontally layered liquefiable grounds using the finitedifference program FLAC ${ }^{3 \mathrm{D}}$. "Finn-Byrne" cyclic load volumetric strain increment model simulates the fluid-solid coupling of saturated sand and the increase in pore water pressure
\end{abstract}


during vibration. The numerical model was loaded using an acceleration sine wave for dynamic calculations. The numerical results showed that the burial depths have a strong influence on the liquefaction of the soil beneath the utility tunnels and on the forces and deformations of the structures. Under the numerical simulation conditions in this paper, the greater the burial depth, the greater the liquefaction of the soil beneath the structure, the greater the shear stress on the side walls and the smaller the settlement difference between the structure and the surrounding soil. In the numerical simulations in this paper, a reasonable burial depth for utility tunnels was 0.8 to 1.1 times of the structure height.

Keywords : Utility tunnel; Finite-difference; Layered liquefiable soils; Burial depth; Soil liquefaction

\section{Introduction}

Growing urbanization and increasing urban populations worldwide have led to a huge demand for reliable infrastructure, and the use of underground space can help cities meet these increased demands(Makdisi and Seed, 1978). Urban underground utility tunnels effectively use the underground space of the city and centralize the arrangement of multiple municipal pipelines, which not only beautifies the city's environment but also facilitates the management of pipelines. Therefore, more and more cities are building and using utility tunnels. There are many cases of soil liquefaction causing damage to underground structures in previous seismic events, such as 1995 Hyogoken-Nambu earthquake (Tokimatsu and Asaka, 1998), 2010 Chile 
earthquake (Kang et al., 2013), and 2011 Great East Japan Earthquake (Chian et al., 2014). The more widely utility tunnels are used, the more their safety deserve greater attention, especially in cities located in seismically active areas. The utility tunnel is a typical segmented long-line underground structure with lighter mass and usually shallow burial depth in the project, and the main part is usually made up of small sections of $20 \mathrm{~m}-30 \mathrm{~m}$ connected by joints. The characteristics of utility tunnels determine that one of the most serious risks in case of soil liquefaction is uneven settlement, which can lead to damage such as joint failure and internal pipe misalignment. At the same time, the force state of utility tunnels in liquefied soils is altered, causing structural deformation and damage to weak areas, etc., which eventually make them lose their working performance.

Loose saturated sand is subjected to cyclic loads such as earthquakes, the strength and shear modulus of the soil decreases, while the pore water pressure in the soil increases sharply, the effective stress decreases, and the soil changes from solid to liquid state. In previous studies, a large number of numerical simulations and model tests have discussed the seismic performance of utility tunnels(Chen et al., 2012; Chen et al., 2010; Ding et al., 2020; Jiang et al., 2010; Tang et al., 2020), but there are fewer studies on the forces and deformations of utility tunnels in large liquefied soils.

Currently, most studies of underground structures in liquefied soils are carried out in homogeneous liquefied soils (Ling et al., 2003; Liu and Song, 2005a; Mahmoud et al., 2020; Watanabe et al., 2016; Zhuang et al., 2015). In reality, however, underground structures are 
mostly built in layered soil profiles. This paper investigated urban utility tunnels in horizontally layered liquefiable grounds. The upper and lower layers of the soil profile are impermeable cohesive soils (labelled Coh) and the middle layer is a thicker liquefiable sand layer (labelled Liq), the stratigraphy is abbreviated as "Coh-Liq-Coh", as shown in Fig. 1. In addition, underground structures with circular or single- compartment rectangular cross-sections have been studied more frequently in the past (Chen et al., 2018; Lee et al., 2017; Liu and Song, 2005b; Miao et al., 2018; Unutmaz, 2014; Yang et al., 2004), while trunk utility tunnels are more often in the form of multi-compartment rectangles, so the structural form used in this study was a rectangular three-compartment utility tunnel.

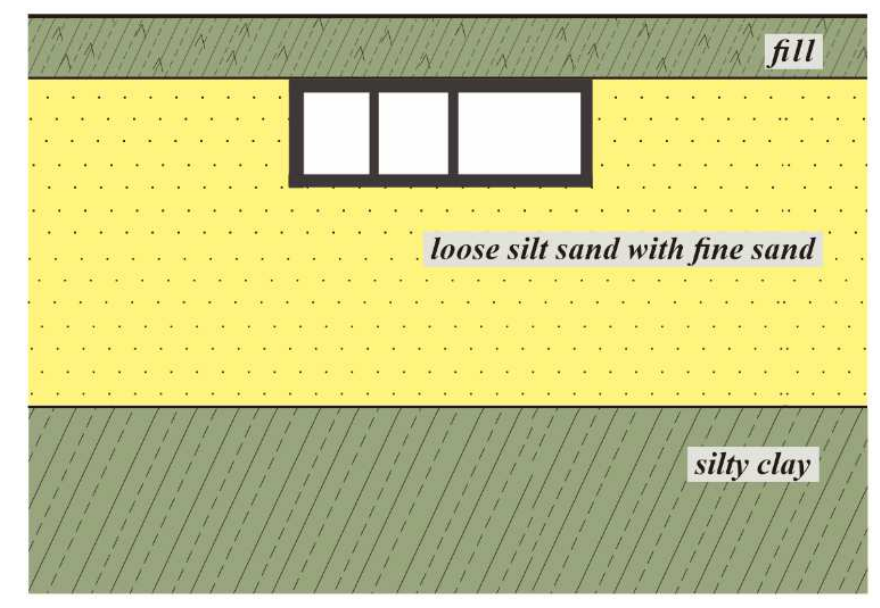

Illustration of the "Coh-Liq-Coh" stratigraphic section.

This paper placed the rectangular three-compartment utility tunnel in a typical "Coh-LiqCoh" layered liquefied soils, focusing on the effect of the structure on soil liquefaction under different burial depth conditions; the forces and deformations of the structure in the liquefied soil under different burial depth conditions; and finally, judging the reasonable burial depth 
based on the numerical simulation results. Nonlinear large deformation analysis of continuous media using the three-dimensional explicit function finite difference program FLAC $^{3 \mathrm{D}}$. The constitutive model of liquefiable sand was adopted from the built-in Finn model of FLAC ${ }^{3 \mathrm{D}}$. Finn model can simulate the liquefaction characteristics of loosely saturated sand, so the numerical model can simulate the properties of underground structures in liquefied soils under cyclic loading (Byrne et al., 2004; Sudevan et al., 2020; Viand and Eseller-Bayat, 2017; Wu and Hsieh, 2014).

\section{Numerical model and parameter setups}

\subsection{Analysis conditions and procedure}

In this study, a $22 \mathrm{~m}$ thick layered saturated soil was assumed in which the rectangular three-compartment utility tunnel is located, as shown in Fig. 2. The "Coh-Liq-Coh" layered liquefiable soils were overlain by a $2 \mathrm{~m}$ thick layer of clay, the middle layer was the liquefiable sand layer where the utility tunnel was located, $15 \mathrm{~m}$ thick, and the lower layer was also clay, $5 \mathrm{~m}$ thick. The design of the utility tunnel in the numerical model was based on the utility tunnel of the Beijing Daxing International Airport trunk line. The structure has a width B of $11.6 \mathrm{~m}$, a height $\mathrm{H}$ of $4.1 \mathrm{~m}$ and a longitudinal dimension of $25 \mathrm{~m}(11.6 \mathrm{~m} \times 4.1 \mathrm{~m} \times 25 \mathrm{~m})$, comprising a communications compartment (2.6 m wide), an electrical compartment ( $2.8 \mathrm{~m}$ wide) and an integrated compartment ( $4.8 \mathrm{~m}$ wide). The thickness of structural side walls, top slab and bottom slab is $0.45 \mathrm{~m}$, and the thickness of structural partition walls are $0.25 \mathrm{~m}$. In this paper, 
the burial depths of the structure in the soil were different. The distances between the top slab of the utility tunnel and the ground surface in the five numerical simulation scenarios were $2 \mathrm{~m}$, $3 \mathrm{~m}, 4 \mathrm{~m}, 5 \mathrm{~m}$ and $6 \mathrm{~m}$ respectively. The bottom of the model was a clay layer, therefore a flexible bottom boundary condition was used for inputting seismic motion at the bottom of the model. The four lateral boundaries of the model were set as free field boundaries in the dynamic analysis to simulate a semi-infinite field. The water level is assumed to be at the ground surface. Details of the numerical model, including soil models, boundary conditions, and input motions, are presented in the following sections.

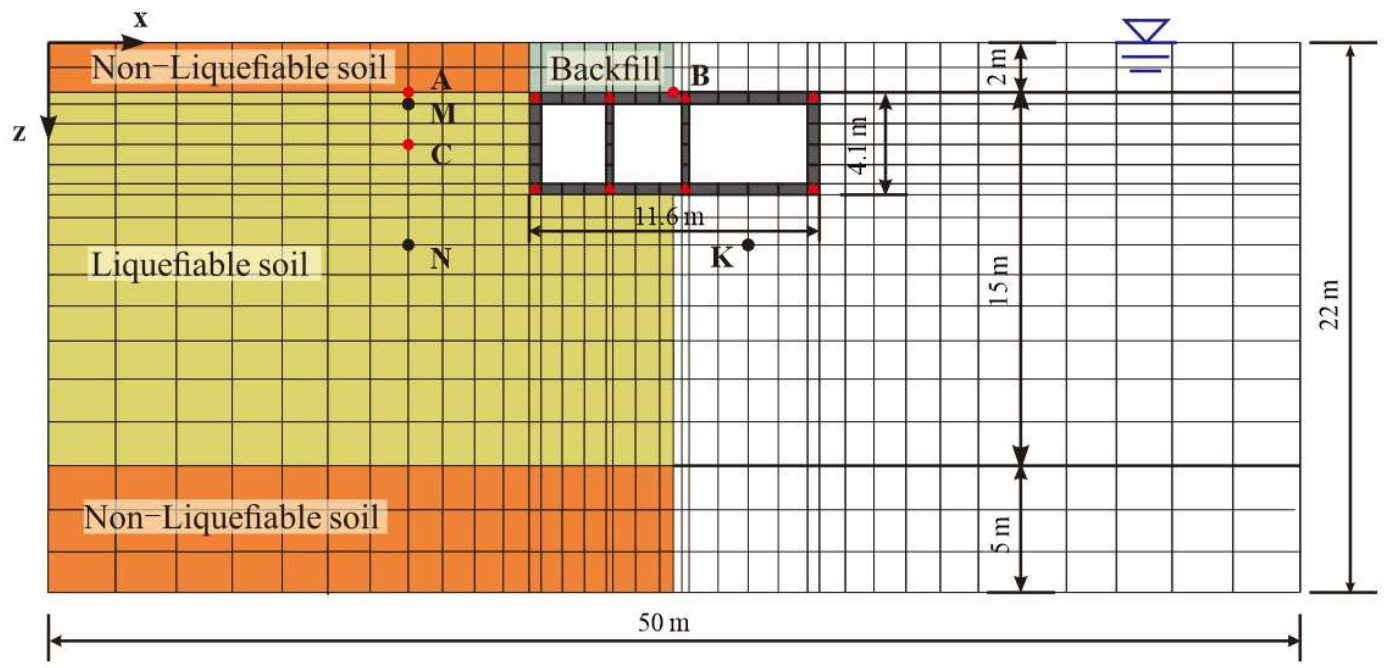

Stratigraphic distribution, gridding and location of monitoring points for numerical model with burial depth of $2 \mathrm{~m}$.

\subsection{Soil and structural models}

The upper and lower parts of the numerical model in this paper were impermeable clay layers. The Earthquake occurs suddenly and the shaking time is short, therefore it can be 
assumed that the saturated sand layer is undrained during the ground shaking process and the cyclic shear strain causes a rise in pore water pressure and liquefaction of the sand.

A large amount of previous test data shows that the volumetric compressive strain in sand soils is caused by cyclic shear strain due to the coupling of the shear response with the volume response. The "Finn-Byrne" sand model used in this paper is able to reflect the coupling of shear and volume in sand under cyclic loading. Martin (Martin et al., 1975) established fourparameter equations for irrecoverable volumetric strain, $\varepsilon_{v}$, and cyclic shear strain, $\gamma$, based on engineering experience and laboratory data. Based on that, Byrne (Byrne, 1991) established a two-parameter equation for volume-shear coupling by dividing the irrecoverable volumetric strain, $\varepsilon_{v}$, and the volumetric strain increment, $\Delta \varepsilon_{v}$, by the shear strain:

$$
\frac{\Delta \varepsilon_{v}}{\gamma}=\mathrm{C}_{1}^{\mathrm{c}} \quad \exp \left(-\mathrm{C}_{2}^{\mathrm{c}}\left(\frac{\varepsilon_{v}}{\gamma}\right)\right)
$$

In the first loading cycle $\varepsilon_{v}=0$, therefore:

$$
\begin{aligned}
& C_{1}=\frac{\left(\Delta \varepsilon_{v}\right)_{\text {cycle } 1}}{\gamma} \\
& C_{2}=0.4 / C_{1}
\end{aligned}
$$

It can be seen that the parameter $C_{1}$ controls the amount of change in volume strain.

$C_{2}$ controls the shape of the curve of the variation of the accumulated volume strain with the number of cycles.

$C_{1}$ and $C_{2}$ are related, as shown in Equation (3), but the presence of $C_{2}$ makes the application of Equation (1) more flexible when complete experimental data are available.

Byrne gave an empirical formula for the parameter $C_{1}$, which can be calculated from the 
relative density, $D_{r}$, of the sand:

$$
C_{1}=7600\left(D_{r}\right)^{-2.5}
$$

In cyclic shear loading, the total volume strain increment, $\Delta \varepsilon_{v}$, in each half cycle is divided into two parts, one for the recoverable elastic volume strain increment, $\Delta \varepsilon_{v}^{e}$, and one for the irrecoverable plastic volume strain increment, $\Delta \varepsilon_{v}^{p}$ :

$$
\Delta \varepsilon_{v}=\Delta \varepsilon_{v}^{e}+\Delta \varepsilon_{v}^{p}
$$

Under simple shear conditions, the elastic volume strain increment can be calculated from the change in effective stress in $1 / 2$ cycle and the tangential modulus of the effective stress of the restrained rebound of the sand skeleton, M:

$$
\Delta \varepsilon_{v}^{e}=\frac{\Delta \varepsilon_{v}^{\prime}}{M}
$$

Under saturated undrained conditions, $\Delta \varepsilon_{v} \approx 0$, so that

$$
\Delta \sigma_{v}^{\prime}=-M \Delta \varepsilon_{v}^{p}
$$

Under conditions of no change in total stress, the increase in pore water pressure is equal to the decrease in effective stress, $\Delta \mathrm{u}=-\Delta \sigma_{v}^{\prime}$.

Therefore, an equation for the incremental plastic volume strain versus the incremental pore water pressure can be developed:

$$
\Delta \mathrm{u}=M \Delta \varepsilon_{v}^{p}
$$

The pore water pressure in any cyclic shear strain, $u_{g}$, can be expressed by a simple summation of the pore water pressure increments, $u_{g}=\sum \Delta \mathrm{u}$.

In this paper, sand parameters were determined by relative density, $D_{r}$, and shear wave 
velocity, $V_{S}$. The relative density of loosely saturated sand in this paper was set to $30 \%$ and the shear wave velocity was set to $100 \mathrm{~m} / \mathrm{s}$ (Mahmoud et al., 2020). The maximum shear module, $\mathrm{G}_{0}$, was determined based on the value of $V_{s}$ from the elastic relationship between $\mathrm{G}_{0}$ and $v_{s}$, $G_{0}=\rho \times V_{S}^{2}$. By assuming a Poisson ratio (v) of 0.33 , the bulk modulus of soil $\left(K_{0}\right)$ was determined from $G_{0}$.

In the soil profile, the clay (non-liquefied soil) in the upper and lower layers was modelled by the Mohr-Coulomb model. Material parameters for non-liquefied soils, including elastic modulus $\left(E_{N}\right)$, Poisson's ratio $\left(v_{N}\right)$, cohesion $(c)$ and friction angle $\left(\varphi_{N}\right)$, were obtained from engineering experience.

A three-dimensional numerical model was established with a longitudinal dimension of 25 $\mathrm{m}$. Both the structure and the soil were simulated using solid elements. The utility tunnel was modelled using elastic model with the material params shown in Table 1.

Table.1 Numerical parameters of materials used in this study

\begin{tabular}{llllll}
\hline \multicolumn{2}{l}{ Sand parameters } & \multicolumn{2}{l}{$\begin{array}{l}\text { Non-liquefiable } \\
\text { parameters }\end{array}$} & \multicolumn{2}{l}{$\begin{array}{l}\text { Structure \& interface } \\
\text { parameters }\end{array}$} \\
\hline$D_{r} \%$ & 30 & $E_{N}(\mathrm{MPa})$ & 40 & $E_{S}(\mathrm{GPa})$ & 30 \\
$G_{0}(\mathrm{MPa})$ & 15 & $v_{N}$ & 0.33 & $v_{s}$ & 0.2 \\
$K_{0}(\mathrm{MPa})$ & 40 & $\rho_{N d}\left(\mathrm{~kg} / \mathrm{m}^{3}\right)$ & 1600 & $\rho_{s d}\left(\mathrm{~kg} / \mathrm{m}^{3}\right)$ & 2500 \\
$\rho_{d}\left(\mathrm{~kg} / \mathrm{m}^{3}\right)$ & 1500 & $c(\mathrm{kPa})$ & 30 & $k_{S}(\mathrm{GPa} / \mathrm{m})$ & 1 \\
$\varphi^{\circ}$ & 33 & $\varphi_{N}{ }^{\circ}$ & 24 & $k_{n}(\mathrm{GPa} / \mathrm{m})$ & 1 \\
$k(\mathrm{~m} / \mathrm{s})$ & $1.02 E-04$ & $k_{N}(\mathrm{~m} / \mathrm{s})$ & $1.00 E-06$ & $\delta^{\circ}$ & $22-23$ \\
$n_{1}$ & 0.43 & $n_{2}$ & 0.4 & $T_{s}$ & 0 \\
$C_{1}$ & 1.54 & $K_{W}(\mathrm{GPa})$ & 2 & $S_{s}$ & 0 \\
$C_{2}$ & 0.26 & & & & \\
\hline
\end{tabular}


Sand parameters. $\mathrm{D}_{\mathrm{r}}$ : relative density; $\mathrm{G}_{0}$ : initial shear modulus at a confining pressure of $100 \mathrm{kPa} ; \mathrm{K}_{0}$ : initial bulk modulus at a confining pressure of $100 \mathrm{kPa}$; $\rho_{\mathrm{d}}$ : dry density; $\varphi$ : angle of internal friction; $\mathrm{k}$ : soil permeability; $\mathrm{n}_{1}$ : porosity; $C_{1}, C_{2}$ liquefaction parameters.

Non-liquefiable parameters. $\mathrm{E}_{\mathrm{N}}$ : non-liquefiable soil young modulus; $\mathrm{v}_{\mathrm{N}}$ : non-liquefiable poisson ratio; $\rho_{\mathrm{Nd}}:$ dry density; c: cohesion; $\varphi_{\mathrm{N}}$ : angle of internal friction; $\mathrm{k}_{\mathrm{N}}$ : soil permeability; $\mathrm{n}_{2}$ : porosity; $\mathrm{K}_{\mathrm{w}}$ : Water modulus.

Structure \& interface parameters. $E_{s}:$ structure young modulus; $v_{s}:$ structure poisson ratio; $\rho_{\text {sd: }}$ structure density; $\mathrm{k}_{\mathrm{s}}$ and $\mathrm{k}_{\mathrm{n}}$ : shear and normal interface stiffness; $\delta^{\circ}$ : friction angle of the interface surface; $\mathrm{T}_{\mathrm{s}}$ : tensile bond strength; $\mathrm{S}_{\mathrm{s}}$ : interface cohesion strength.

The soil-structure interface is represented as normal and shear springs between two nodes in contact with each other. The relative deformations of the normal and shear springs are controlled by the normal stiffness $\left(k_{n}\right)$ and shear stiffness $\left(k_{s}\right)$ values, respectively. $\quad k_{n}$ and $k_{s}$ are set to ten times the maximum equivalent stiffness of adjacent zone.

\subsection{Boundary condition}

The numerical simulation process was divided into a static stage under gravity and a dynamic stage under the action of a horizontal sine wave. In the first stage (self-weight static analysis), the base boundary was fixed both horizontally and vertically and the lateral boundaries were fixed in the normal direction. In the second stage (seismic analysis), free field boundaries were used laterally to represent the lateral extent of the far field, and quiet boundary was used at the bottom. The quiet boundary eliminates the input velocity or acceleration and in order to input seismic motion at the quiet boundary, the acceleration wave needs to be converted to a stress wave. In this paper a sine wave was input in the form of stress at the nodes at the 
bottom of the model along the horizontal direction. The shear stress, $\sigma_{s}$, determined from input shear particle velocity, $v_{s}$, as:

$$
\sigma_{s}=2\left(\rho C_{s}\right) v_{s}
$$

Where $\rho$ and $C_{s}$ are the mass density and speed of s-wave propagation through medium, respectively.

\subsection{Input motion}

The details of the input seismic wave have an important influence on the response of the soil. Even if the control params of the input seismic waves (maximum acceleration, mainshock frequency, strong seismic holding time, etc.) are exactly equivalent, the effects of seismic waves with different waveforms on the structure is different (Makdisi and Seed, 1978). However this paper focused on the impact of saturated sand liquefaction on the utility tunnel. In order to reduce the difference in results caused by the use of different forms of seismic waves, the numerical simulation used sine waves for loading. The peak acceleration of the acceleration sine wave in this paper is $0.3 \mathrm{~g}$, the vibration frequency is $5 \mathrm{~Hz}$, and the duration is $12 \mathrm{~s}$ (ZhanFang et al., 2021). The acceleration gradually increases from 0 to the maximum value in $0-2 \mathrm{~s}$. The stable period is 2-6 s, followed by a decreasing period, and the acceleration gradually decreases to 0 in 6-12 s, as shown in Fig. 3. 


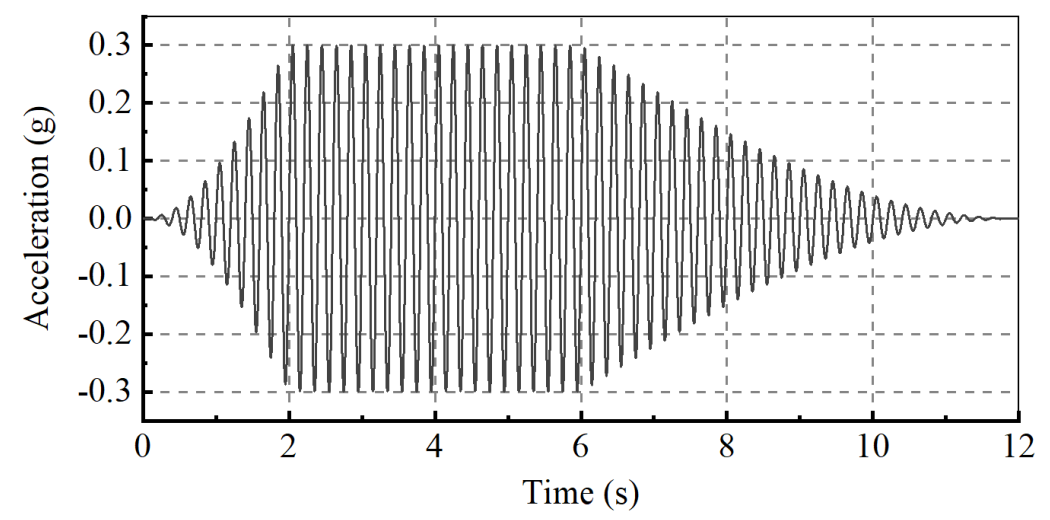

Time history of acceleration sine waves.

\section{Liquefaction characterisation of soils and structures}

\subsection{Seepage and displacement of the soil}

In this paper, section $\mathrm{S}$ is chosen as the monitoring surface for acceleration, excess pore water pressure, pore pressure and effective stress of the soil. The monitoring surface $\mathrm{S}$ is the middle section perpendicular to the longitudinal direction in the numerical model, as shown in Fig. 2. The left side of the figure shows the distribution of the "Coh-Liq-Coh " stratum and the right side shows the meshing of the numerical simulation.

In this section we illustrate the typical liquefaction characteristics of layered liquefiable soils and structure using the example of the utility tunnel buried at a depth of $2 \mathrm{~m}$ (the top slab of the structure is at $2 \mathrm{~m}$ below ground surface). Under cyclic shear loading, the pore water pressure in the saturated undrained sand layer increases and seepage forms, Fig. 4(a) shows the seepage vector at section $\mathrm{S}$ at the end of the dynamic loading. A certain amount of water flows upwards in the "Liq" sand layer. The pore water pressure in the non-liquefied undrained layer 
remains constant during shaking, while the pore water pressure in the liquefied sand layer increases, so that the seepage vector at the soil intersection points to the side with less pore water pressure. In the saturated sand layer, the flow is high in the upper and lower parts and low in the middle. The flow in the soil directly below the structure is high and the flow on the sides is low.

(a)

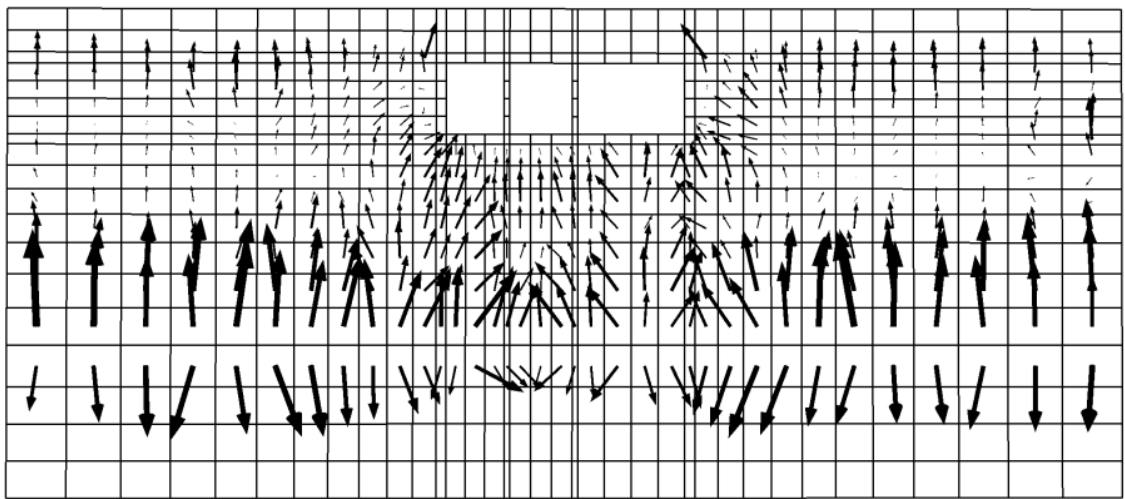

(b)

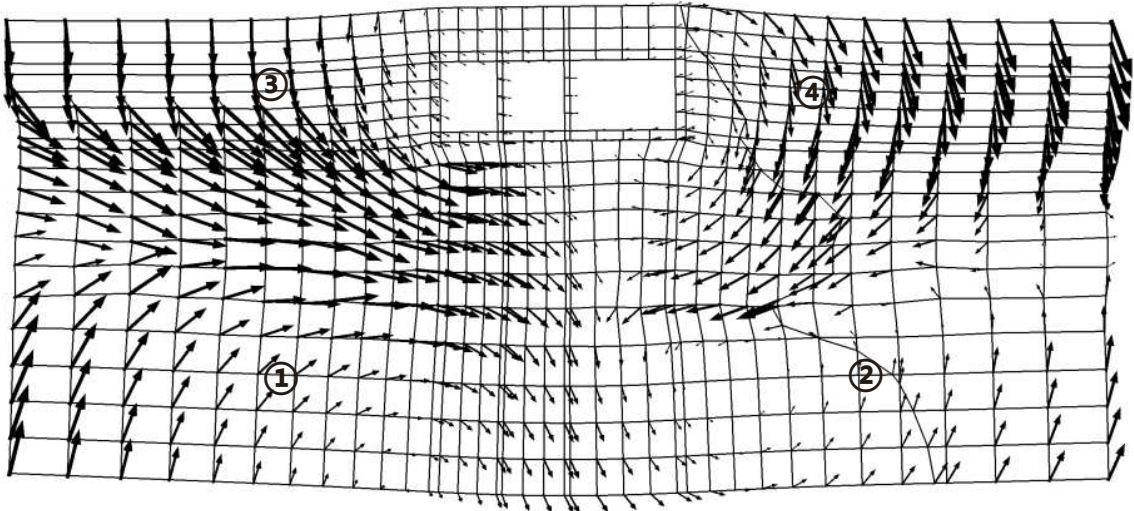

Soil liquefaction results at the cross section at the midpoint of the lengthwise axis of the

numerical model, (a) Seepage vector distribution; (b) grid deformation and soil displacement vectors.

Previous engineering experiences show that uneven settlement of the structure and soil caused by soil movement is the main cause of damage to underground structures. Utility tunnel is light underground structure with a total structural density less than the surrounding soil 
density. Fig. 4(b) shows the displacement vector of the soil and the structure. During the vibration, the soil around the utility tunnel moved towards the underside of the structure bottom slab and the underground structure uplifts.
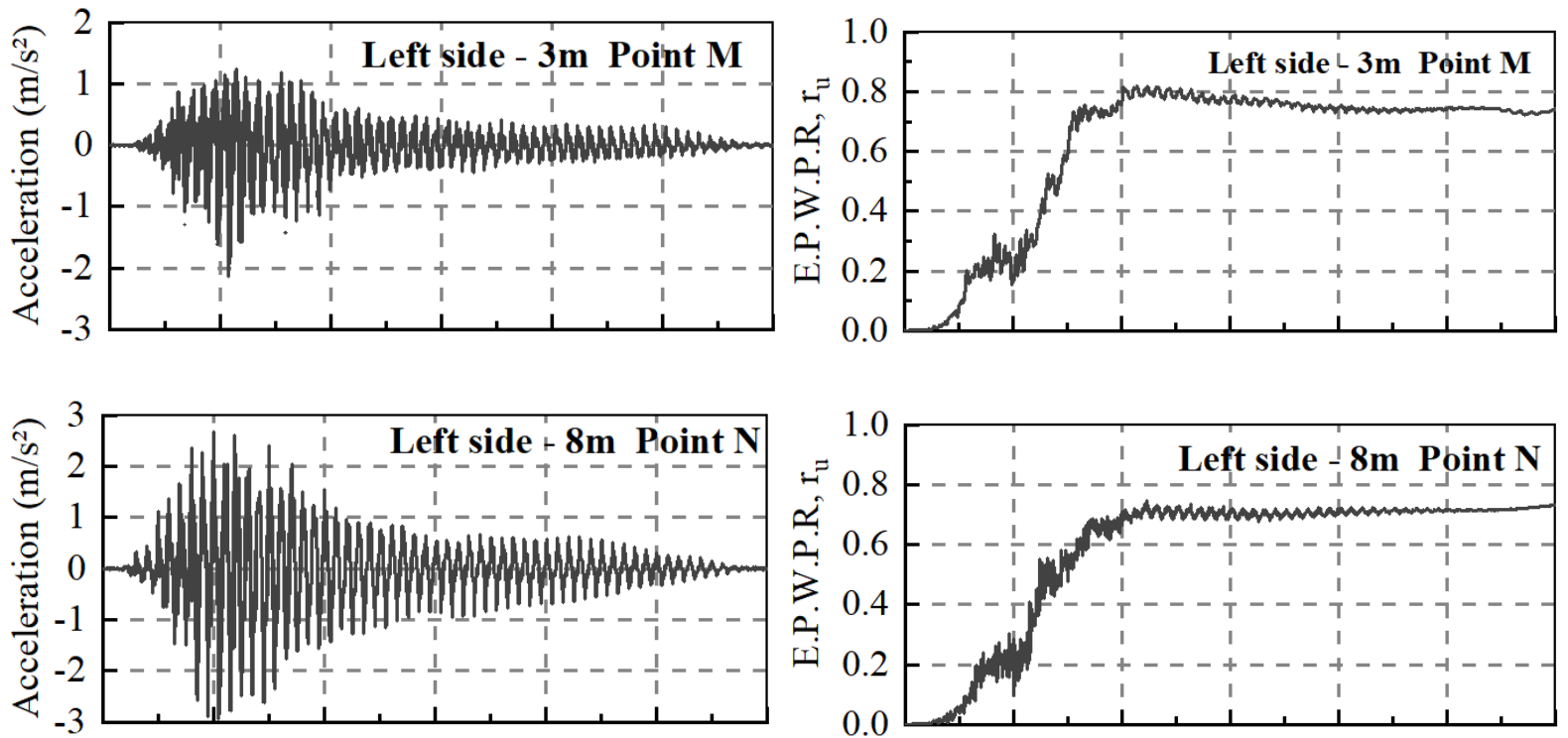

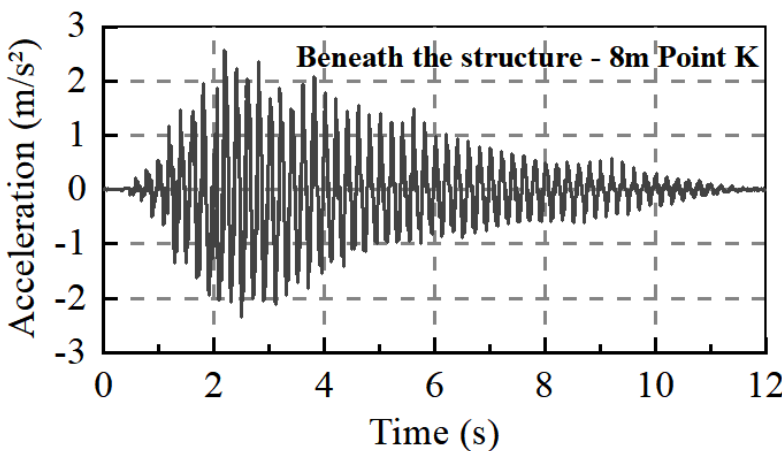

(a)

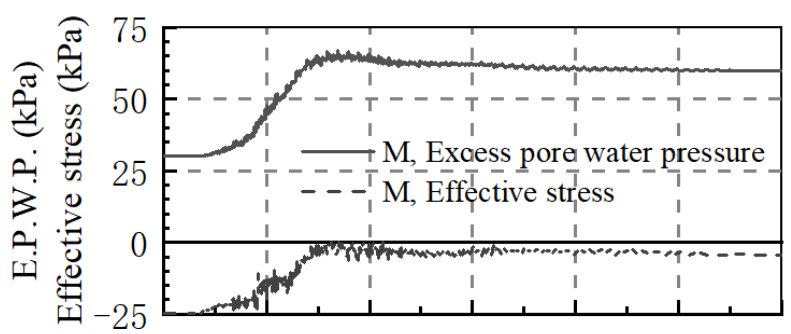

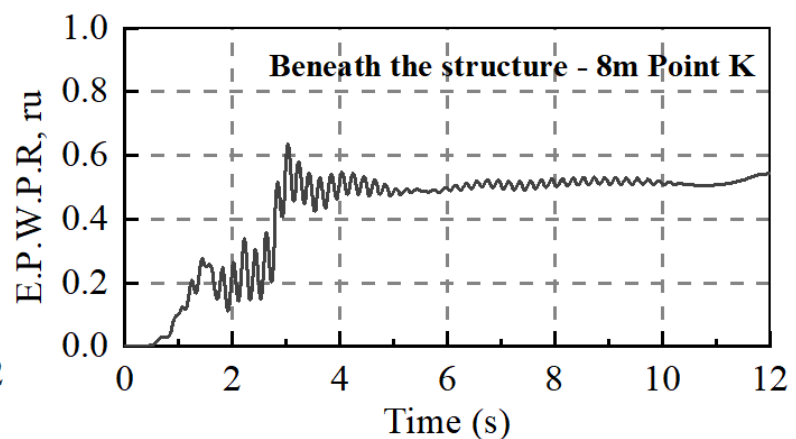

(b)

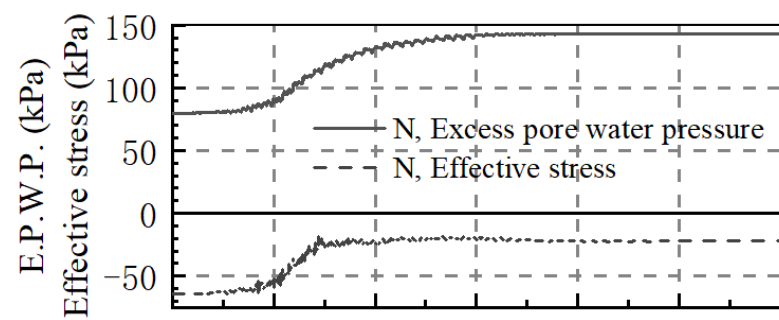




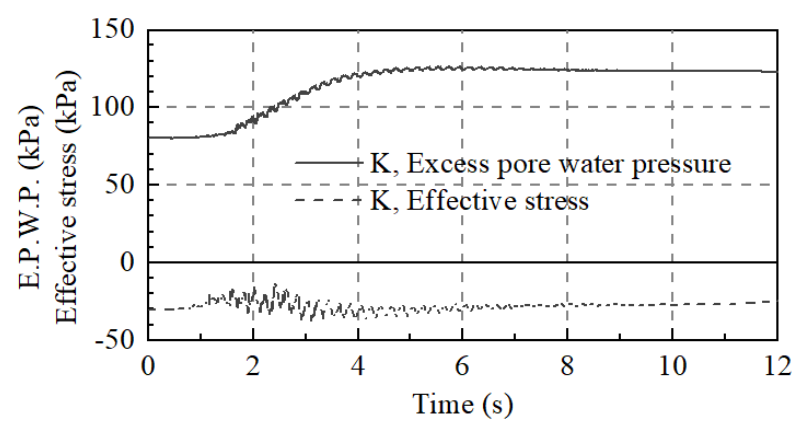

(c)

Typical soil response at points $\mathrm{M}, \mathrm{N}$ and $\mathrm{K}$ for the structure buried at a depth of $2 \mathrm{~m}$ : time histories of (a) acceleration, (b) excess pore water pressure ratio, (c) pore water pressure and effective stress.

\subsection{Soil liquefaction}

Liquefaction is defined as the loss of shear strength of the soil. The soil gradually changes from a solid to a liquid state and the amplitude of the soil velocity and acceleration decays. Fig. 5(a) shows the time histories of soil acceleration at different locations. points $\mathrm{M}$ and $\mathrm{N}$ are located to the left of the structure and point $\mathrm{K}$ is located in the soil below the structure and the monitoring points information is shown in Fig. 2. Compared to the acceleration of the input seismic wave, there was a significant attenuation of the acceleration at the three points. The attenuation of the acceleration at point $\mathrm{M}$ was more pronounced.

In numerical calculations, the excess pore water pressure ratio represents the degree of liquefaction of the soil, with $r_{u}$ equal to 1 indicating complete liquefaction and $r_{u}$ above 0.7 indicating that the soil is close to liquefaction. Fig. 5(b) shows the time histories of the excess pore water pressure ratio (EPWPR) at points $\mathrm{M}, \mathrm{N}$ and $\mathrm{K}$. The EPWPR started small, increased steadily and rapidly after $2 \mathrm{~s}$ until $4 \mathrm{~s}$, after which the EPWPR remained stable until the end of 
the earthquake. The EPWPR stable values at points $\mathrm{M}$ and $\mathrm{N}$ were 0.8 and 0.7 respectively, and the EPWPR stable value at point $\mathrm{K}$ was approximately 0.5. A comparison of Fig. 5 (a) and (b) show that the increase in the excess pore water pressure ratio of the soil corresponds to a decrease in its acceleration. The EPWPR at point $\mathrm{N}$ increased to 0.7 at around $4 \mathrm{~s}$ and the acceleration at point $\mathrm{N}$ also decreased significantly at around $4 \mathrm{~s}$. The accumulation of pore water pressure and the reduction of effective stress in the soil under cyclic load action is one of the important characteristics of soil liquefaction. In Fig. 5(c), the variation of pore water pressure and effective stress at points $\mathrm{M}, \mathrm{N}$ and $\mathrm{K}$ were consistent with the state of liquefaction exhibited by the sand in Fig. 5 (a) and (b).

\subsection{Vertical displacements of the structure}

Fig. 6 shows the time histories of vertical displacement at point B in the top slab of the utility tunnel and point $\mathrm{A}$ in the left soil. Continuous settlement at point $\mathrm{A}$ for a period of $6 \mathrm{~s}$ from the start of the shaking, with a maximum settlement of $12.2 \mathrm{~mm}$, after which the settlement remained stable. There was a small settlement of the soil at point B from the start of the shaking to $2.8 \mathrm{~s}$, due to volume contraction of the loose sand beneath the structure as a result of the shaking. During liquefaction, the soil moved towards the underside of the structure's bottom slab, point B gradually uplifted to $3.8 \mathrm{~mm}$ and then remained stable. There was a settlement difference between the utility tunnel and the surrounding soil, as shown in Fig. 4(a). 


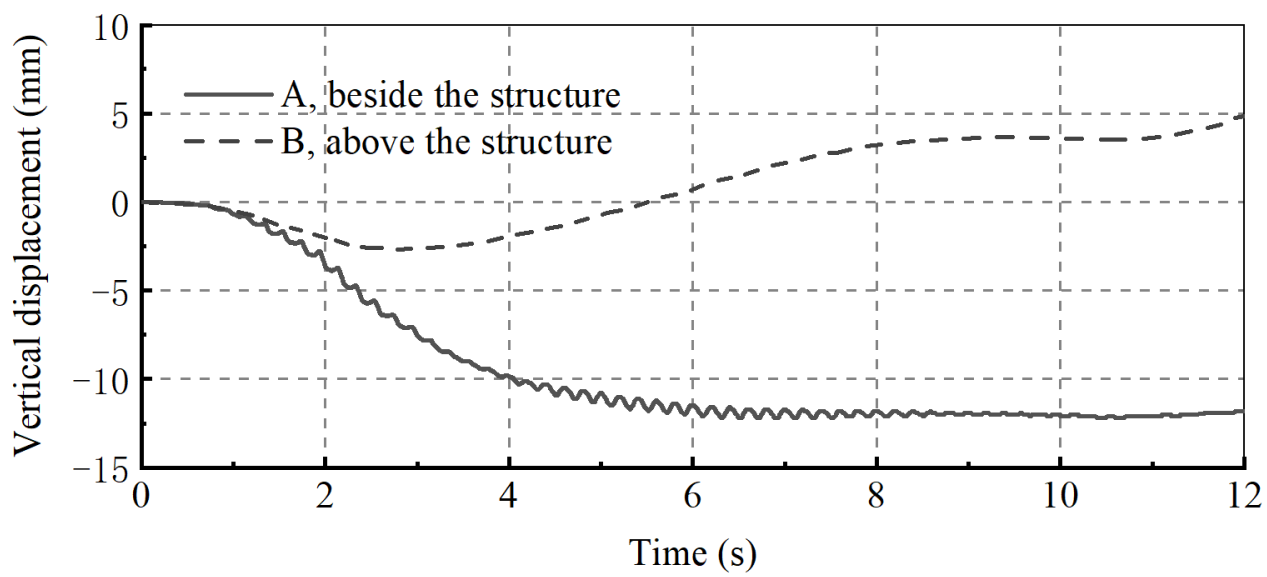

Time history of vertical displacements at points $A$ and $B$ at 2 m burial depth.

\section{Effect of different burial depths}

\subsection{Effect of burial depths on soil liquefaction}

It is generally accepted that the shallower the burial depth of the utility tunnel, the lower the cost of the project, provided that the design requirements are met. However, in layered liquefied soils, soil liquefaction can lead to uplift of the structure if the burial depth is too shallow. Therefore, a reasonable depth of burial of the structure needs to be determined. Five options of burial depths of $2 \mathrm{~m}, 3 \mathrm{~m}, 4 \mathrm{~m}, 5 \mathrm{~m}$ and $6 \mathrm{~m}$ were set in this paper to determine the reasonable burial depth of the utility tunnel.

Fig. 7 shows the time histories of the EPWPR of the soil at point K, $2 \mathrm{~m}$ below the bottom slab of the structure, for five different sets of burial depth conditions. The monitoring position of point $\mathrm{K}$ changed with the burial depth of the structure. At a burial depth of $2 \mathrm{~m}$, the stable EPWPR of the soil at point $\mathrm{K}$ was approximately 0.5 . When the structure was buried at $3 \mathrm{~m}, 4$ $\mathrm{m}$ and $5 \mathrm{~m}$, the EPWPR curves of the soil reached 0.65 at around $9 \mathrm{~s}, 7 \mathrm{~s}$ and $5 \mathrm{~s}$. At a burial 
depth of $6 \mathrm{~m}$, the EPWPR of the soil at point $\mathrm{K}$ reached 0.75 . This indicates that in "Coh-LiqCoh" layered liquefied soils, the deeper the utility tunnel is buried, the greater the liquefaction of the soil beneath the structure.
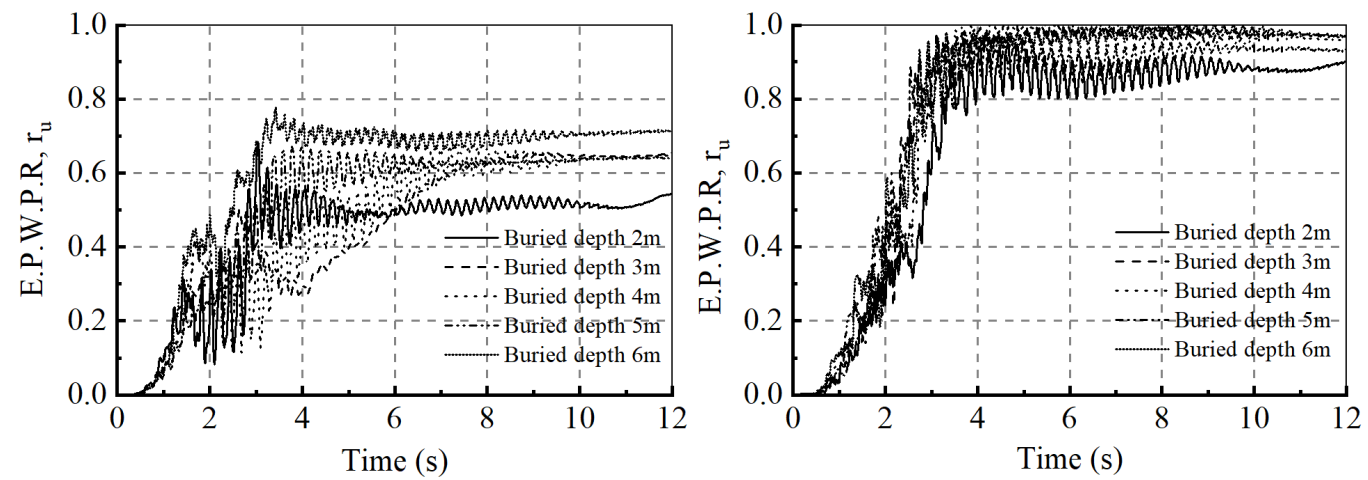

Time history of excess pore water pressure at point $\mathrm{K}$ for structures at different burial depths.

Time history of excess pore water pressure at point $\mathrm{C}$ for structures at different burial depths.

Fig. 8 shows the EPWPR time histories for monitoring point $\mathrm{C}$ under five different burial conditions, which is located to the left of the structure, at a depth of $5 \mathrm{~m}$ below the surface. The soil at point $\mathrm{C}$ reached liquefaction at all five burial depths, indicating that the depth of burial has little effect on the liquefaction of the soil at more distant locations on the side of the structure.

Fig. 9 shows the excess pore water pressure ratio clouds for the final state of the crosssection $\mathrm{S}$ for four different burial depth conditions. In this paper, the liquefied sand layer was divided into three parts; zone I was the soil directly below the structure, zone II was the soil to the left and right of the structure, and zone III was the soil beneath the sides of the structure. As shown in Fig. 9, the extent and degree of liquefaction of soil in Zone I increased with burial depth. In zone II, the soil closer to the structure were more affected by it, and the EPWPR values 
for the soils close to the sides of the structure were below 0.5 for all five burial conditions, and no liquefaction occurred. Zone III was farther away from the structure and was less influenced by it, with little variation in the extent of liquefaction.

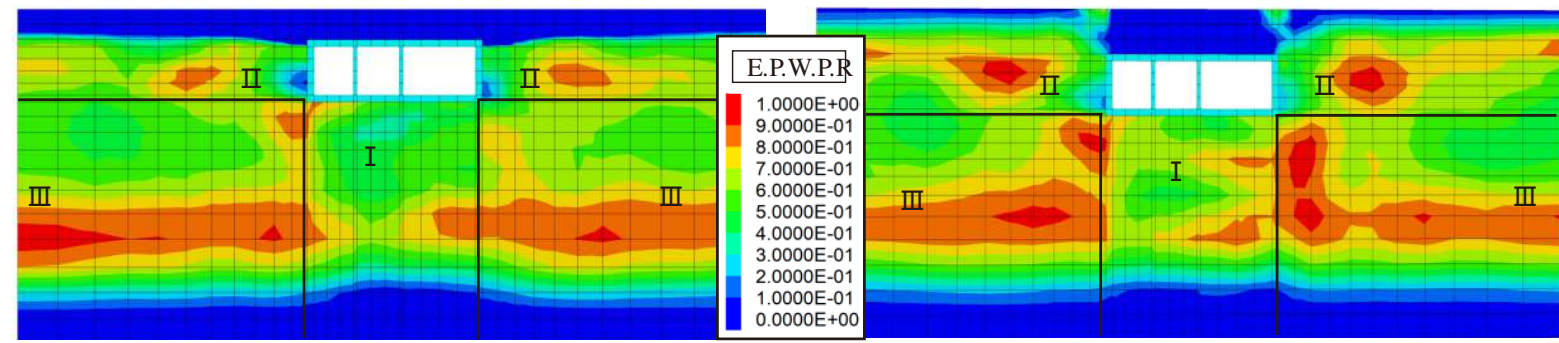

(a)

(b)

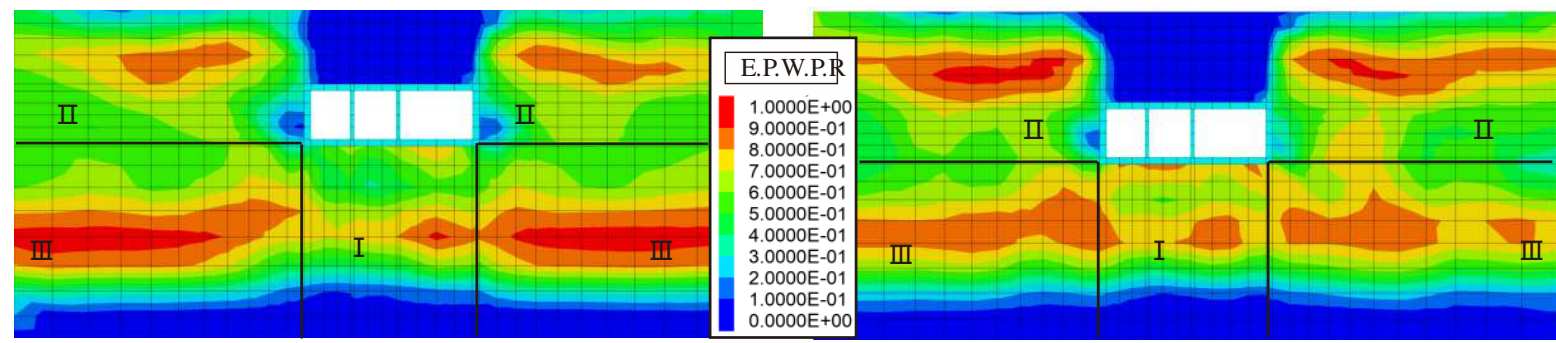

(c)

(d)

Cloud plot of excess pore water pressure ratio for the final state of the cross section at the midpoint of the lengthwise axis of the model for different burial depth conditions: (a) Burial depth 2m, (b) Burial depth 3 m, (c) Burial depth 5 m, (d) Burial depth 6 m.

\subsection{Effect of burial depth on vertical displacement of the structure}

Differential settlement between the utility tunnel and the surrounding soil is one of the main factors causing structural damage. Fig. 10 shows the absolute value of the difference in vertical displacement difference between point B at the top slab of the structure and point A in the soil (the position of points A and B varies with depth of burial). The settlement difference between point $\mathrm{A}$ and point $\mathrm{B}$ decreased with increasing depth of burial, the settlement difference between points A and B at a burial depth of $6 \mathrm{~m}$ was $30.2 \%$ of that at a burial depth of $2 \mathrm{~m}$. 

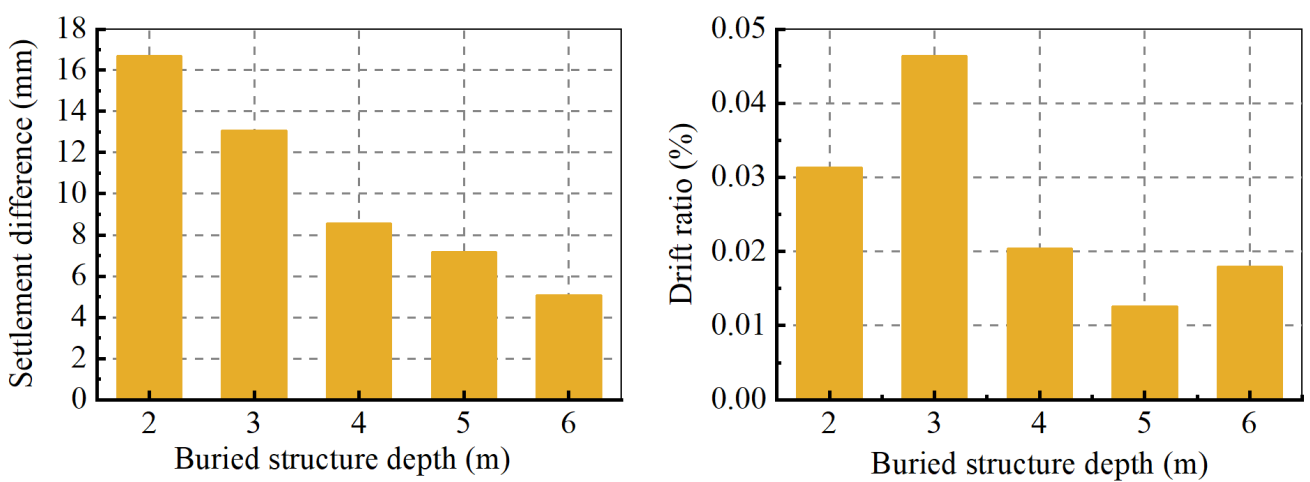

Fig. 10. Settlement difference between point $A$ and point $B$ for different burial depth conditions.

Fig. 12. Maximum drift ratios of structural side walls and partition walls for different burial depths.

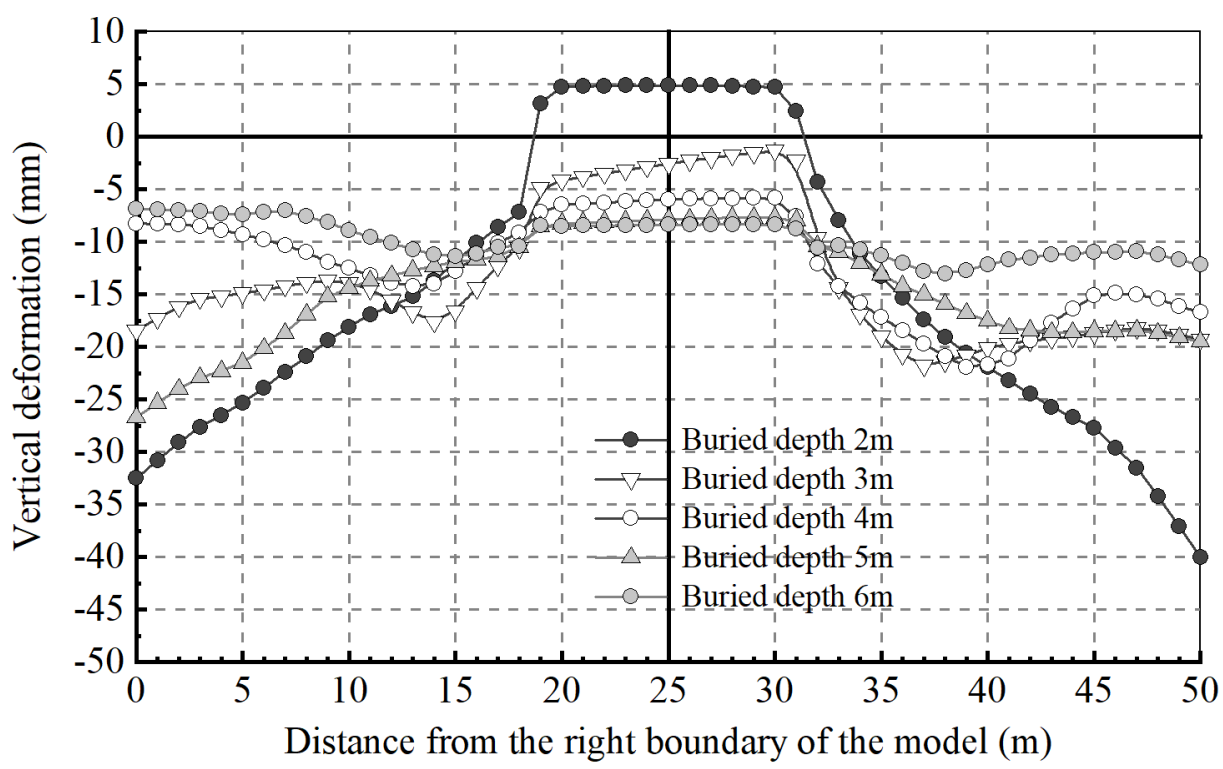

Fig. 11. Vertical displacement values of soil monitoring points on the horizontal surface of the structure bottom slab for five different burial depth conditions.

Fig. 11 shows the vertical displacement values of the soil on the same level as the bottom slab of the structure for five different conditions at the end of the shaking. Starting at the left boundary of the model and ending at the right boundary of the model, monitoring points were selected at $1 \mathrm{~m}$ intervals. At a burial depth of $2 \mathrm{~m}$, the soil on both sides settled significantly 
and the settlement difference between the soil and the structure was greatest. As the burial depth of the structure increased, the settlement at the monitoring point decreased and so did the settlement difference.

\subsection{Effect of burial depth on structural deformation and forces}

In this paper, the deformations and forces of the structure were represented by drift ratio and shear stress. The drift ratio is the absolute difference in lateral displacement between the top and bottom of the underground structure normalized by the height of the structure. Based on Eurocode 8 (Code, 2005) and CCSDB (Standard, 2010), the drift rate should be limited to $1.0 \%, 0.7 \%$ and $0.4 \%$ respectively, and in this paper $0.4 \%$ should be used as the limit, while the shear should be within the design capacity value.

The rectangular three-compartment utility tunnel has two side walls and two partition walls, all four of which need to meet the limits of the drift ratio. Fig. 12 shows the maximum values of drift ratios for these four walls in different burial depth conditions. The maximum drift ratio of the wall at a burial depth of $5 \mathrm{~m}$ was $27 \%$ of that at a burial depth of $3 \mathrm{~m}$. In this study, the drift ratio values in all five conditions were well below the thresholds of the adopted performance criteria. 

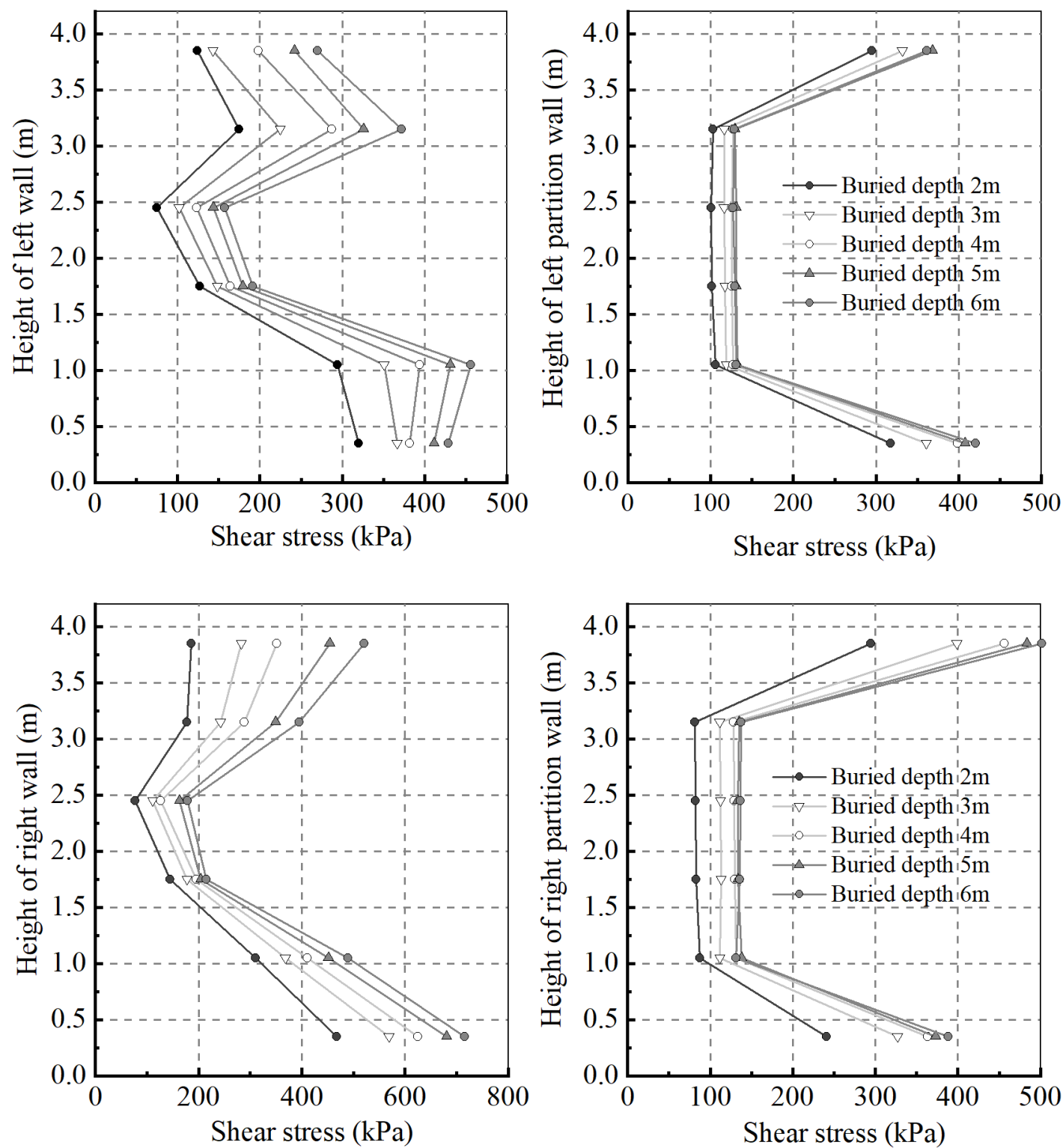

Fig.13. Maximum shear stresses in structural side walls and partition walls for five burial depth conditions: (a) shear stress distribution on the left wall, (b) shear stress distribution on the left partition wall, (c) shear stress distribution on the right wall, (d) shear stress distribution on the right partition wall.

Fig.13 shows the average distribution of the maximum shear stresses along the left wall, left partition wall, right partition wall and right wall for the five different structural burial conditions. As the depth of burial increases, the shear stresses distributed across the walls 
became greater. The distribution of shear stresses in the walls showed a roughly concave shape, with the distribution of shear stresses in the left and right walls being greater than those in the partition walls. The maximum shear stress occurred at the intersection of the wall with the top and bottom slabs. In all conditions, the maximum shear stresses were within the bearing capacity. Fig. 14 shows the maximum shear stress curve at the base of the right wall for different burial depth conditions. Within the depth range set in this paper, the maximum shear stresses increased linearly with increasing the buried depth.

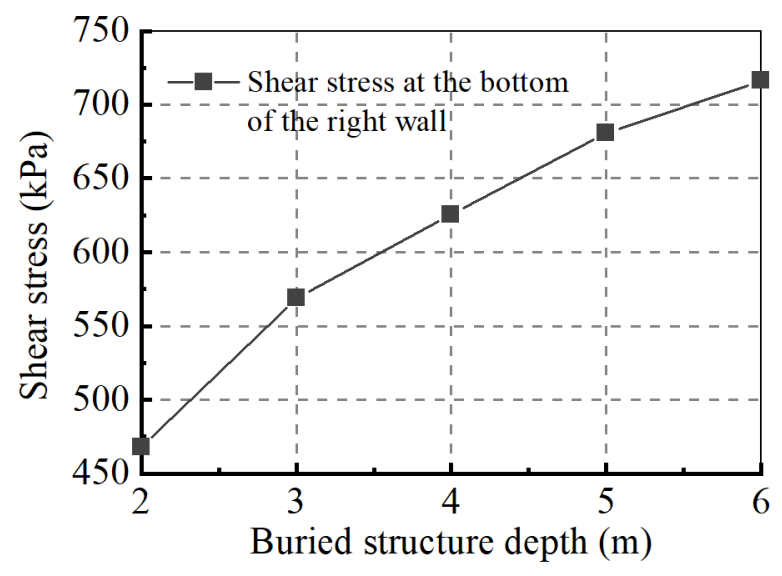

Fig.14. Maximum value of shear stress at the bottom of the right wall for five burial depth conditions.

\section{Conclusion}

This paper used the finite-difference software FLAC ${ }^{3 \mathrm{D}}$ to investigate a rectangular threecompartment utility tunnel in typical "Coh-Liq-Coh" layered liquefiable soils with different burial depths. The model was loaded using a sine wave with a peak acceleration of $0.3 \mathrm{~g}$ to simulate a seismic wave. The "Finn-Byrne" cyclic load-carrying strain incremental model was 
used for liquefiable sands and the Mohr-Coulomb elastoplastic constitutive model was used for non-liquefiable soils. This paper investigated the effect of structures on soil liquefaction under different burial depth conditions and the forces and deformations of structures in liquefied soils. Vertical displacement, drift ratio and shear stress were used to calculate the dynamic response of the underground structure.

Earthquakes cause liquefaction of layered liquefiable soils. The soil on both sides of the structure moved towards the underside of the structure bottom slab, causing uneven settlement of the structure and the soil, creating a convex rise in the ground with a high centre and low sides, which in turn causes structural damage.

The different burial depths had a greater impact on the soil beneath the structure than the soil on either side of the structure. As the depth of burial increased, the extent of liquefaction of the soil beneath the structure increased and the degree of liquefaction became higher. Lateral soils further away from the structure were largely unaffected by changes in the depth of burial of the structure. When the structure was buried at a shallow depth, the settlement of the soil to the left and right of the structure and its differential settlement with the structure were both large, while both gradually decreased with increasing depth of burial. The drift ratios and shear stresses of the structure were within the limits and the drift ratios were much less than their limit value. The shear stresses in the wall increased linearly with depth of burial and could cause shear damage to the utility tunnel during more intense seismic activity. The above conclusions on the effect of burial depths on the structure were based on the burial depths ( $2 \mathrm{~m}$ to $6 \mathrm{~m})$ set in 
the numerical simulations in this paper. In previous studies, for deeply buried structures, the dynamic response of the structure eventually decreases as the depth of burial increases.

A comparison of the five different burial depth options showed that burial depth had a significant effect on the underground structure; a reasonable burial depth for the utility tunnel in this paper was 0.8 to 1.1 times the height of the structure. The effects of seismic features, the proportional relationship between the depth of burial and the dimensions of the underground structure, and the thickness of the liquefiable and non-liquefiable layers on the underground structure need to be further investigated.

\section{Acknowledgements}

The authors would like to thank the National Natural Science Foundation of China (No. 51578023) for funding the work presented in this paper.

\section{References}

Byrne, P.M. (1991) A cyclic shear-volume coupling and pore pressure model for sand.

Byrne, P.M., Park, S.-S., Beaty, M., Sharp, M., Gonzalez, L., Abdoun, T. (2004) Numerical modeling of liquefaction and comparison with centrifuge tests. NRC Research Press Ottawa, Canada 41

Chen, J., Jiang, L., Li, J., Shi, X. (2012) Numerical simulation of shaking table test on utility tunnel under non-uniform earthquake excitation. Tunnelling and Underground Space Technology incorporating Trenchless Technology Research 30 
Chen, J., Shi, X., Li, J. (2010) Shaking table test of utility tunnel under non-uniform earthquake wave excitation. Soil Dynamics and Earthquake Engineering 30, 1400-1416, DOI: 10.1016/j.soildyn.2010.06.014.

Chen, R., Taiebat, M., Wang, R., Zhang, J.-M. (2018) Effects of layered liquefiable deposits on the seismic response of an underground structure. Soil Dynamics and Earthquake Engineering 113

Chian, S.C., Tokimatsu, K., Madabhushi, S.P.G. (2014) Soil Liquefaction-Induced Uplift of Underground Structures: Physical and Numerical Modeling. Journal of Geotechnical and Geoenvironmental Engineering 140, 04014057, DOI: 10.1061/(asce)gt.1943-5606.0001159.

Code, P. (2005) Eurocode 8: Design of structures for earthquake resistance-part 1: general rules, seismic actions and rules for buildings. Brussels: European Committee for Standardization

Ding, X., Feng, L., Wang, C., Chen, Z., Han, L. (2020) Shaking table tests of the seismic response of a utility tunnel with a joint connection. Soil Dynamics and Earthquake Engineering 133

Jiang, L., Chen, J., Li, J. (2010) Seismic response of underground utility tunnels: shaking table testing and FEM analysis. Earthquake Engineering and Engineering Vibration 9, 555-567, DOI: $10.1007 / \mathrm{s} 11803-010-0037-\mathrm{x}$.

Kang, G.-C., Tobita, T., Iai, S., Ge, L. (2013) Centrifuge Modeling and Mitigation of Manhole Uplift due to Liquefaction. Journal of Geotechnical and Geoenvironmental 
Engineering 139, 458-469, DOI: 10.1061/(asce)gt.1943-5606.0000769.

Lee, C.-J., Wei, Y.-C., Chuang, W.-Y., Hung, W.-Y., Wu, W.-L., Ho, T.-Y., 2017. Uplift Mechanism of Rectangular Tunnel in Liquefied Soils. Springer Japan, pp. 61-74.

Ling, H.I., Mohri, Y., Kawabata, T., Liu, H., Burke, C., Sun, L. (2003) Centrifugal Modeling of Seismic Behavior of Large-Diameter Pipe in Liquefiable Soil. Journal of Geotechnical and Geoenvironmental Engineering 129

Liu, H., Song, E. (2005a) Effects of burial depth on the liquefaction response of underground structures during an earthquake excitation. Journal of Tsinghua University (Science\&Technology) 45, 301-305

Liu, H., Song, E. (2005b) Seismic response of large underground structures in liquefiable soils subjected to horizontal and vertical earthquake excitations. Computers and Geotechnics 32, 223-244, DOI: 10.1016/j.compgeo.2005.02.002.

Mahmoud, A.O., Hussien, M.N., Karray, M., Chekired, M., Bessette, C., Jinga, L. (2020) Mitigation of liquefaction-induced uplift of underground structures. Computers and Geotechnics 125, 103663, DOI: 10.1016/j.compgeo.2020.103663.

Makdisi, F.I., Seed, H.B. (1978) SIMPLIFIED PROCEDURE FOR ESTIMATING DAM AND EMBANKMENT EARTHQUAKE-INDUCED DEFORMATIONS. Journal of the Geotechnical Engineering Division-Asce 104, 849-867

Martin, G.R., Finn, W.D.L., Seed, H.B. (1975) Fundamentals of Liquefaction Under Cyclic Loading. Journal of the Geotechnical Eng. 101 
Miao, Y., Yao, E., Ruan, B., Zhuang, H. (2018) Seismic response of shield tunnel subjected to spatially varying earthquake ground motions. Tunnelling and Underground Space Technology 77, 216-226, DOI: 10.1016/j.tust.2018.04.006.

Standard, P.N. (2010) Code for seismic design of buildings (GB 50011-2010), The Ministry of Housing and Urban-Rural Construction of the People's Republic of China. Beijing, China: China Architecture \& Building Press

Sudevan, P.B., Boominathan, A., Banerjee, S. (2020) Numerical Study of LiquefactionInduced Uplift of Underground Structure. International Journal of Geomechanics 20

Tang, G., Fang, Y., Zhong, Y., Yuan, J., Ruan, B., Fang, Y., Wu, Q., Shi, P. (2020) Numerical Study on the Longitudinal Response Characteristics of Utility Tunnel under Strong Earthquake: A Case Study. Advances in Civil Engineering 2020

Tokimatsu, K., Asaka, Y. (1998) EFFECTS OF LIQUEFACTION-INDUCED GROUND DISPLACEMENTS ON PILE PERFORMANCE IN THE 1995 HYOGOKEN-NAMBU EARTHQUAKE. SOILS AND FOUNDATIONS 38, 163-177, DOI: 10.3208/sandf.38.special_163.

Unutmaz, B. (2014) 3D liquefaction assessment of soils surrounding circular tunnels. Tunnelling and underground space technology 40, 85-94

Viand, S.M.S., Eseller-Bayat, E.E., 2017. Numerical Modelling of Liquefaction Tests of Partially Saturated Sands in CSSLB. Springer International Publishing, pp. 501-508.

Watanabe, K., Sawada, R., Koseki, J. (2016) Uplift mechanism of open-cut tunnel in 
liquefied ground and simplified method to evaluate the stability against uplifting. Soils and Foundations 56, 412-426, DOI: 10.1016/j.sandf.2016.04.008.

Wu, Y.C., Hsieh, M.H. (2014) Site Response Analysis for a Site with the Dipping Bedrock and Liquefiable Layers Using FLAC 3D. Applied Mechanics and Materials 2872

Yang, D., Naesgaard, E., Byrne, P.M., Adalier, K., Abdoun, T. (2004) Numerical model verification and calibration of George Massey Tunnel using centrifuge models. NRC Research Press Ottawa, Canada 41

Zhan-Fang, H., Bai, X.-H., Yin, C., Liu, Y.-Q. (2021) Numerical analysis for the vertical bearing capacity of composite pile foundation system in liquefiable soil under sine wave vibration. PLOS ONE 16, e0248502, DOI: 10.1371/journal.pone.0248502.

Zhuang, H., Hu, Z., Wang, X., Chen, G. (2015) Seismic responses of a large underground structure in liquefied soils by FEM numerical modelling. Bulletin of Earthquake Engineering 13, 3645-3668, DOI: 10.1007/s10518-015-9790-6. 